for while abdominal aneurism in the fomale is of very rare cocurrence, inorganic aortic pulsation is very common. Preal accumulation and impaction has been mistaken for aneurism of the abdominal aorta. The oval shape of the tumour, with its doughy, inelastic feel, and the result of free purgation, will, in general, suffice to clear up the diagnosis.

Fnlarged glands, or organic disease of the abdominal viscera, either lying over, or pressing laterally upon the artery, will sometimes closely simulate aneurism. The history of the cases, and especially the existence of malignant disease in other parts of the body will aid our opinion; while in pulsation from superimposed tumours, the murmur may often be interrupted by change of position, or by applying the stethoscope laterally, und displacing the tumour from off the artery. The obscurity of symptoms and pain accompanying lumbar and psoas abscess may resemble the phenomena of aneurisin; but the swelling, elongating downwards, without sound or impulse, and the want of the globular tumour of the enlarged artery, will, in general, distinguish these affections.

Tumours of the kidney may, by extending irregularly inwards, and receiving the shock of the artery, sometimes resemble an aneurismal swelling; but the condition of the urine, and previous history of the case, will sufficiently assist the diagnosis. It should be borne in mind, however, that an aneurism pressing upon the emulgent vein may render the urine albuminous. In all cases in which the symptoms are obscure-and in very many they will inevitably prove at first to be so-it will be advisable to examine the patient both in the erect, horizontal, and lateral postures, and, in some instances, it may be prudent to watch the case for a time before risking an opinion.

\section{CASE OF ARM AND SHOULDER PRESENTATION IN WHICH EVISCERATION WAS PERFORMED.}

By Robert Manners Mann, Esq., Manchester.

As cases requiring an operation of this description are of rare occurrence, $I$ think the publication of the following in our JourNAI may prove interesting, as well as instructive, to some of our readers.

Case. On Thursday evening, April 3rd, I received an urgent message to attend Mrs. L., aged 22 years, who was said to be in premature labour of her first child. On arriving at her residence, I found her suffering from tolerably strong and expulsive uterine pains. An examination per vaginam informed me that a considerable portion of the bag of membranes was protruded through the os uteri into the ragina, and all but without the os externum. - Neither during a pain nor in the intcrvals between, could I detect any presentation; but I discovered high up ths os uteri, and the not as yet obliterated cervix, shewing me that she was between her sixth and seventh month. The os was perhaps so far dilated as to be capable of receiving two or three fingers.

Strong expulsive efforts continuing, the membranes soon gave way; and I now expected some portion of the foetus to follow shortly. In this, however, I was disappointed; for, although there was an immediate and considerable fow of liquor amnii and much dribbling afterwards, I could only just by pressing my finger firmly upwards perceive that there was a limb of the fotus, but whether an arm or leg, could not make out to my satisfaction. The pains now ceased entirely ; and after waiting some time, I advised my patient to get up, and think no more about it, until the action of the uterus should again be excited. I left strict orders to be sent for on the return of pains, as I have often known delivery take place very suddenly in such premature cases, even in primipara. No message, howerer, came for me till Saturday morning, April 5th, at eight o'clock.

I now found her having both strong and frequent pains; and on examining, discovered the right hand, arm, and shoulder, presenting, together with a very dry, unjielding, and undilatable state of the soft parts. The pains continued to increase in violence; and as the state of parts would not as yet justify me in attempting to turn, I resigned myself patiently to the hope, that as the foetus was premature, and consequently softer and more yielding, that nature's efforts would suffice, or that the possible but unusual circumstance of spontaneous evolution might occur. After waiting a few hours, however, the shoulder only got lower, and the chest more and more firmly wedged in the pelvic carity; but in the mcan time the os uteri was becoming more dilated, and I therefore decided upon making an attempt to turn. Using lard freely, I then in the usual way, but with much difficulty, succeeded in passing $\mathbf{m y}$ left hand into the ragina, and afterwards, by long continued pressure through a rigid and strongly resisting os uteri, managed to insinuate it into the uterus. Owing, however, to the two circumstances of the liquor amnii having been so long evacuated, and the vigorous muscular action going on cramping my hand, it was with considerable difficulty that I at length reached what proved afterwards to be the right foot. I could not by any efforts I dare use bring this down more than just barely to shew itself through the labia majora. A slip noose was then made in some tape, and passed over the foot and secured round the ankle, but still all traction failed to make any change, and the arm kept slipping down as fast as I returned it. My patient had suffered very severely, and was getting exhausted, so that after maturc consideration, I decided that evisceration of the fotus would not only afford her speedy relief, but would be the only means left for her delivery. My perforating instruments were soon brought, and I got an assistant to hold the arm and employ traction by it, for me to steady the chest; after which, I was enabled easily to evacuate the contents of the thorax and alsdomen, and directly afterwards hooked my finger in the pelvis, brought down the legs, and without much more trouble the head followed.

There was no doubt whatever in my mind that the fotus had been dead for a considerable period previous to the operation. The pelvis is diminutive. My patient is now (April 16th) sitting up, and progressing in every way extremely well.

\section{A CASE OF STRANGULATED FEMORAL HERNIA, WITH PROTRUSION OF THE INTESTINE ON THE FIFTH DAY : RECOVERY.}

By T. M. WARD, Esq., Exmouth.

CAsE. Mrs. E. H., aged 66 years, a spare but tolerably healthy woman, has fallen under my care several times during the last two years, with strangulated femoral hernia. I have always had considerable difficulty in returning the bowel. The tumour was large and hard, and the symptoms very urgent. In spite of my repeated romonstrances, she neglected to wear a truss regularly; and in this state, with a severe cough, she walked on the 10th of February to Lympstone, two miles from home. While there, the hernia descended, and becamc strangulated. My friend Mr. Price, of that place, was called in, and after a long and patient trial of the taxis, failed in reducing it. He then gave her an injection with a flexible tube, and a pill with three grains of opium, repeating a grain dose every hour. When under the influence of the opiate, he tried the taxis upon her again, unsuccessfully.

On the morning of the 1Jth, she was brought home, and placed under my care, when I repeated the attempt, with a like result. Mr. Price then coming to my aid, we made her inhale chloroform, and then we both made a final but fruitless effort to return the hernia.

Having explained to her the necessity of an immediate operation, to which she at once consented, I procured the kind aid of my friend Mr. Eustace (a retired surgeon), an : at 3 P.x. proceeded to operate. Mr. Price kept her all ine time well under the influence of chloroform, and also afforaed 